\title{
The Art of Renovation Projects on HANOK in AIDIA 2013 Students Workshop
}

\author{
Lin Lei, Lu Jin, Wu Fengzhou \\ Shanghai Academy of Fine Arts, Shanghai University, Shanghai, China \\ Email address: \\ Ilinlei $a 126 . c o m$ (Lin Lei), $1285007487 @$ qq.com (Lu Jin), 285155547@ $a$ qq.com (Wu Fengzhou)
}

\section{To cite this article:}

Lin Lei, Lu Jin, Wu Fengzhou. The Art of Renovation Projects on HANOK in AIDIA 2013 Students Workshop. Journal of Civil, Construction and Environmental Engineering. Vol. 3, No. 4, 2018, pp. 118-124. doi: 10.11648/j.jccee.20180304.14

Received: September 3, 2018; Accepted: September 25, 2018; Published: October 27, 2018

\begin{abstract}
Asia Interior Design Institute Association (AIDIA) is an academic group dedicated to the development of interior design in Asia. It was co-sponsored in 2000 by three Interior Design Society of China, Japan and Korea. Later, it has absorbed academic groups from many countries and regions such as Malaysia, Thailand, the Philippines, Singapore and Taiwan. With the continuous participation of new members, its influence in the academic circles of interior design in Southeast Asia is expanding. Since 2005, the international student's workshop has been held every two year by AIDIA. It hopes to encourage teachers and students participated from different Asian countries to think of the interior design education in the context of oriental culture. It also provided a platform for teachers and students to show their talents. Each workshop will be open to all design school in Asia, and generally comprises about 100 teachers and students altogether that are from more than 20 institutions. AIDIA 2013 Students Workshop was held at Konkuk University Graduate School of Architecture in Seoul, Korea for a week. It involved teachers and students from Korea, China and Thailand. The theme of this workshop was "Renovation Project of Bukchon Hanok village", aiming to explore the protection and renovation of historic and cultural blocks through carrying out with a new dimension of the renovation project of Bukchon Hanok village that is known as the most representative Korean traditional residential area in Seoul. During the activity, students were mixed grouping, and their teachers in the guidance were from different institutions. Finally, the infinite imagination of the housing space in Bukchon Hanok village, the understanding and cognition of design themes, the colliding of ideas between different groups were presented through the form of design works. This paper introduces three projects which had different consideration and exploration in the field of art and design respectively from three different angles: etiquette culture, traditional symbols and Zen ideology.
\end{abstract}

Keywords: AIDIA, Workshop, Protection and Renovation, Historic and Cultural Block, HANOK (Traditional Korean House)

\section{Introduction}

In recent decades, as an effective method of teaching communication, workshop has released the glamour of artistic practice in diverse forms, from which we can see various cultures collide, various ideas emerge, various inspirations meet and various methods be gathered at the right time in short practical training course. Students provide invaluable insight into the beliefs, values, behaviors, mannerisms and prejudices of architectural culture well beyond what we can imagine when they are invited to work collaboratively to understand the interlocking of conceptual and practical missions involved in executing a special shoot.
AIDIA Students Workshop has been held every two year since 2005 and is, unsurprisingly, one of the important activities, which play a very important role in promoting education development of interior design in Asian countries. It has strategies to attract younger students to seek help, to innovate, to create, and so to stretch each of different design teams to display their talents. AIDIA 2013 Students Workshop was held at Konkuk University Graduate School of Architecture in Seoul, Korea, and took us one week to finish the work. It involved teachers and students from Korea, China and Thailand. The workshop offered training on topics that were relevant to strengthening youth engagement to 'Renovation Project of Bukchon Hanok village', a hot topic 
in Asian today. This is probably not desirable that we humans have begun to alter our environment on an increasing scale, sometimes with disastrous consequences. The harsh reality of both HANOK and the world made the students set great store by the effective management of the protection and renovation of cultural heritage in the design process. We also believed that designing well was the key to maximize the benefits of users and to minimize the destruction to HANOK.

'Hanok' in the Korean language means a traditional Korean house [1]. Bukchon Hanok Village is a place where traditional Korean houses are dense and the most representative traditional residence, known as the street museum in the city center [2]. Korean traditional architecture, like Japan, has been deeply influenced by China in terms of construction materials and structural forms and its structural system was the erection of a wooden frame [3]. Its ancient architectural image had impressed every foreign participant (Figure 1-2). Lacking a shared understanding of the term 'cultural heritage' can be problematic and we can see that current situation of protection is contrary to our expectations. With the advent of modern society, however, that changed, and we humans began to alter our environment on an increasing scale, sometimes with disastrous consequences. Therefore, lots of HANOK had been steadily disappearing in the urban development. Some are interspersed with a mixture of some more modern architecture, which seem to be isolated and abrupt. The result is that the buildings connected the roof tiles become more precious.

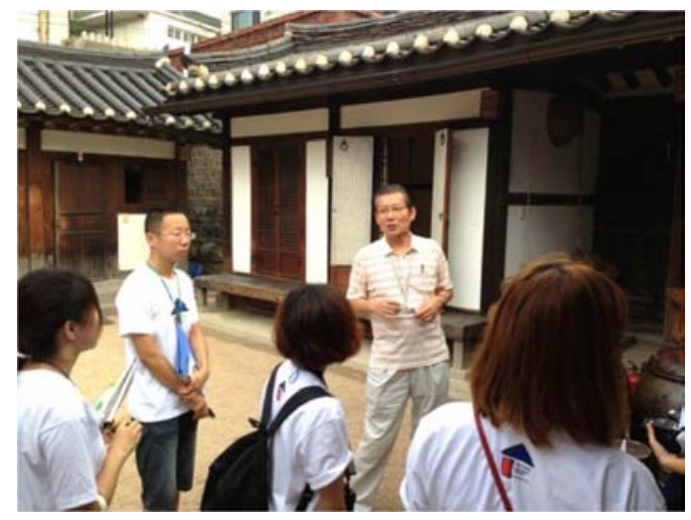

Took by Lin Lei

Figure 1. On-the-spot investigation and interpretation about HANOK of Bukchon village.

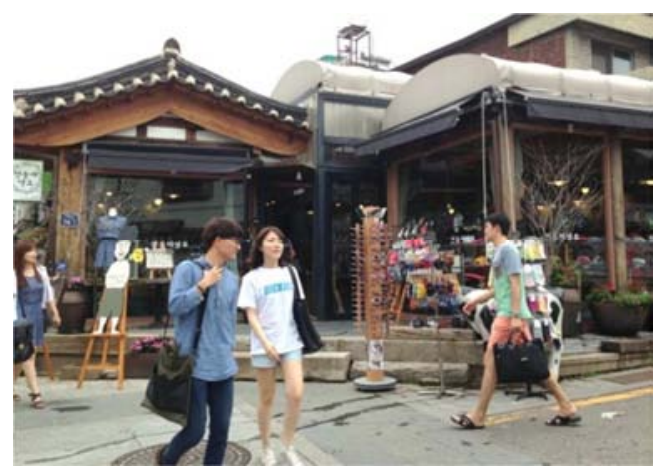

Took by Lin Lei

Figure 2. Street view of modified HANOK.
As a link to the historical context, the workshop was desirable to distinguish three particular standards in which culture manifests itself: 1) observable heritages, 2) culture values, and 3) assumptions underlying surface. A questionnaire survey and interviews, as well as the requirements of a proposed web-based system, were conducted to collect opinions of traditional inheritance on various issues related to the sharing, capture and reuse of knowledge and experience in projects allowed students not only to think about the certain aspects of culture, which were physically visible, but also their meanings that were invisible lying precisely in the way the insider's practices could be interpreted. To really understand a culture and to ascertain more completely the culture values, it was imperative to orderly and continuously delves into the problem-solving methods in the development of Bukchon village, which were easily confounded but actually determined how students should perceive, ponder and judge the research object.

\section{The Artistic Charm of Renovation Project}

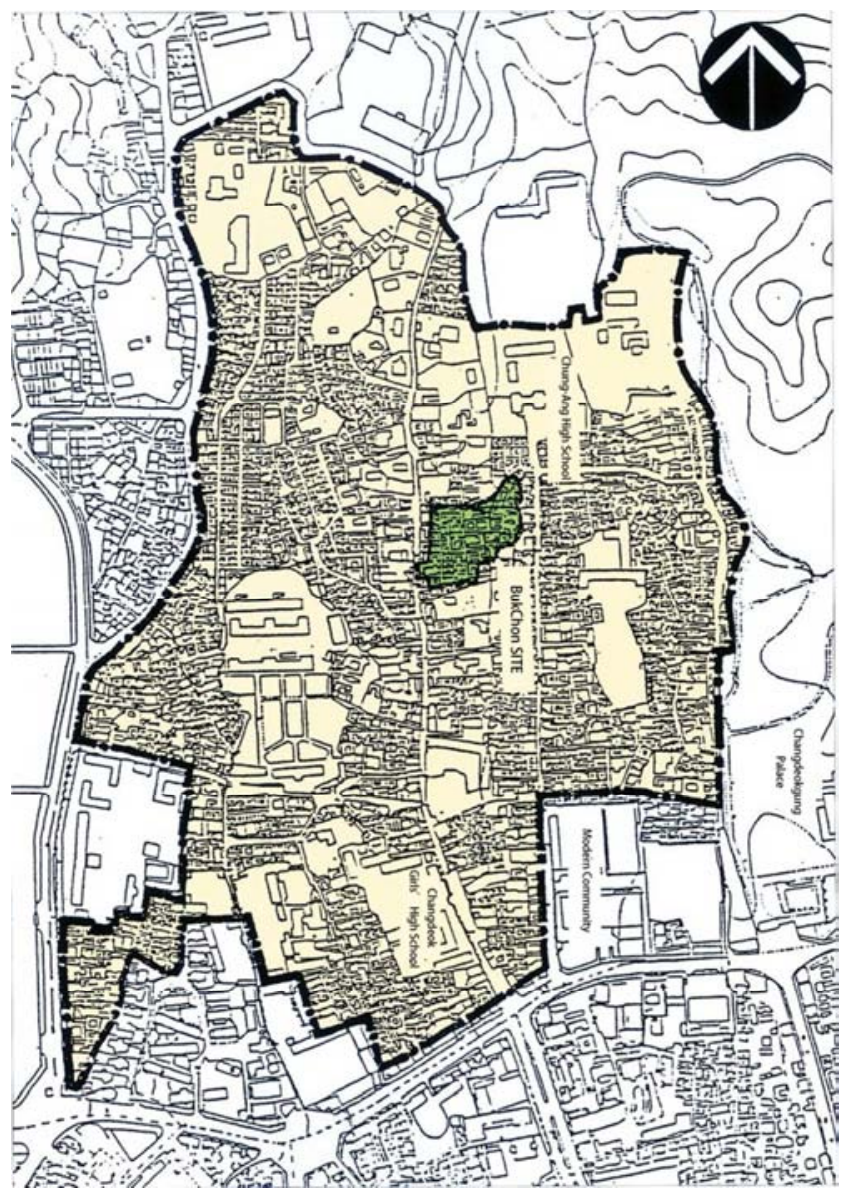

Provided by AIDIA Workshop

Figure 3. General layout of Bukchon village. 


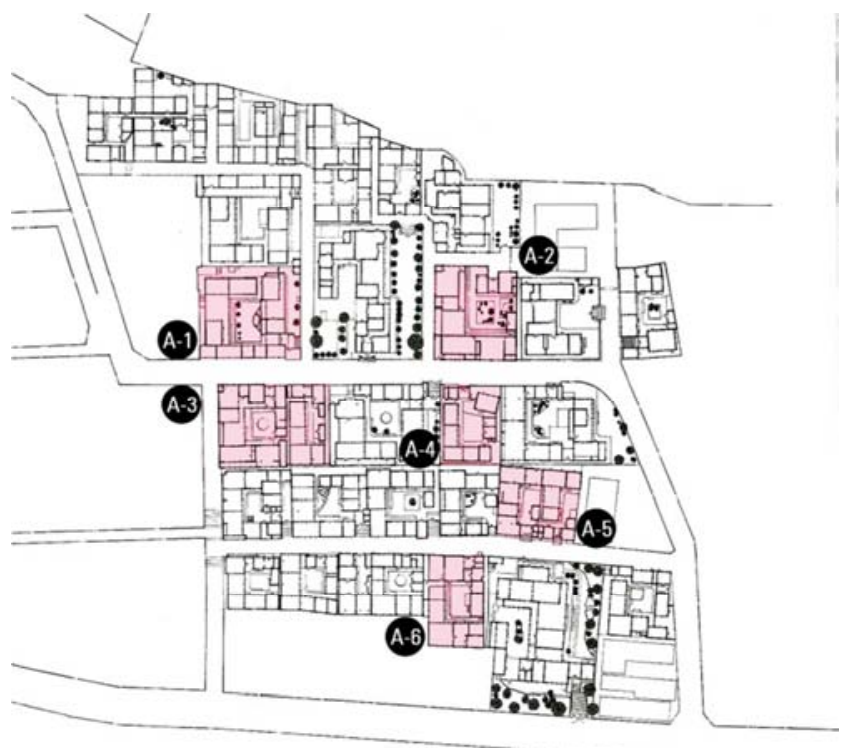

Provided by AIDIA Workshop

Figure 4. Six bases.

Considering the role of Bukchon village in history, eight teams selected one of the six different given bases (Figure 3-4) carefully to conduct each project facing typical problems which were requested providing suitable solutions for the workshop. Any attempt of describing an object without considering the background of Bukchon village would be thrown off the track from the start. In such a scenario, contradictions in different ideologies and concepts often came up: architectural heritage as historical product but perpetual; as material artifact but of an ideal sense; as blurry combination but of their all different aspects. In spite of many complications, the research of each team was both positive and creative, and then continually extended into reception; it implied that the culture known as a power had constantly evolved concepts into a process of preservation or renewal. To give a way to make the complicated process carried on directly, we take three examples here as appreciation candidates and prescribing fruition modes which were based on curriculum design process that we, the teachers and students of Shanghai University, had developed as part of our experience.

\subsection{Etiquette Culture}

The first design proposal being done in the sociocultural context had found that there was a gap in the more complex task of schematic design when applying the theory and models in practice. The students of this team had designed an interesting 'Photo-studio' of Korean etiquette culture by taking five of the seven most important etiquette cultures in Korea: 1) Birth Ceremony, 2) Capping Ceremony, 3) Wedding 4) Family Life, and 5) Hui Jia Festival and Nursing Home (Figure 5-6), which give social meanings to each person's important stages in life. Tracing the source of the etiquette, it was based on Neo-Confucianism spread to Korea from China at the end of the 14th century. One hundred years ago, the etiquette was still prevalent at court and among the literati-official class.

The team presented a visual overview that might be useful in understanding the dwelling culture of HANOK to confirm consistent cultural traits in the transformation of Korean house culture and accession of Korean life-style and identity of Korean residential space. HANOK is divided into the residence of the upper class and lower class by the social class [4]. The residence of the upper class with both practicality and artistry followed the 'Neo-Confucianism' concept and made different space arrangements not only according to gender, age and identity [5]. The general residence of the upper class is divided into the inner and outside space for women and men respectively according to the distinction between inside and outside [6].

Each phase of the design model had offered an opportunity for changes and eventually yielded results to map out 'photo-studio' that laid emphasis on tourist culture. The highlight of this model was to stimulate creative thinking about how to renovate the men space at the entrance into a living museum by removing the non-structural wall and forming a half-naked roof truss system, beneath which it became apparently a semi-open and semi-public space provided for a variety of activities when the different spaces would be occupied by its users (Figure 7-8). Modern elements were also boldly applied to the wall of the building facing the courtyard, forging a strong connection between indoors and outdoors that made the living museum more expansive and light filled.

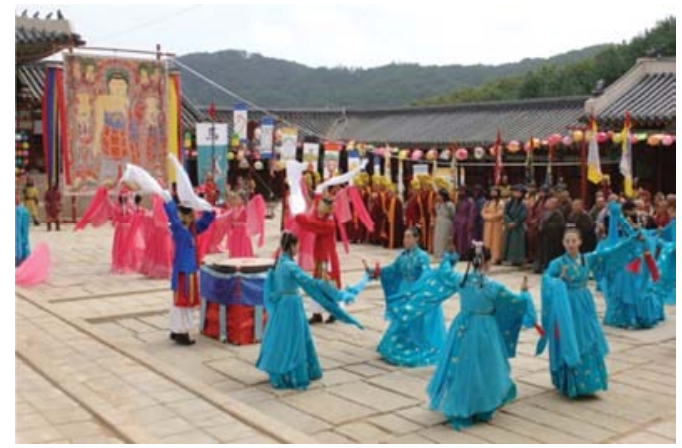

Provided by Team 7 of the AIDIA Workshop

Figure 5. Project 1: Schematic diagram of the etiquette culture of studio-Watching Korean etiquette dance.

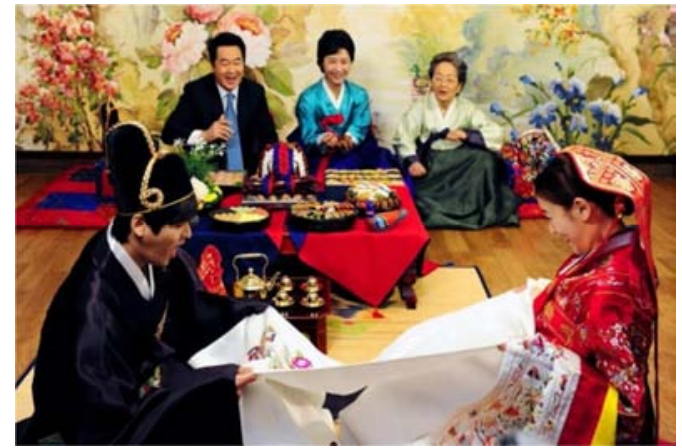

Provided by Team 7 of the AIDIA Workshop

Figure 6. Project 1: Schematic diagram of the etiquette culture of studio-Wearing a hanbok to take pictures. 


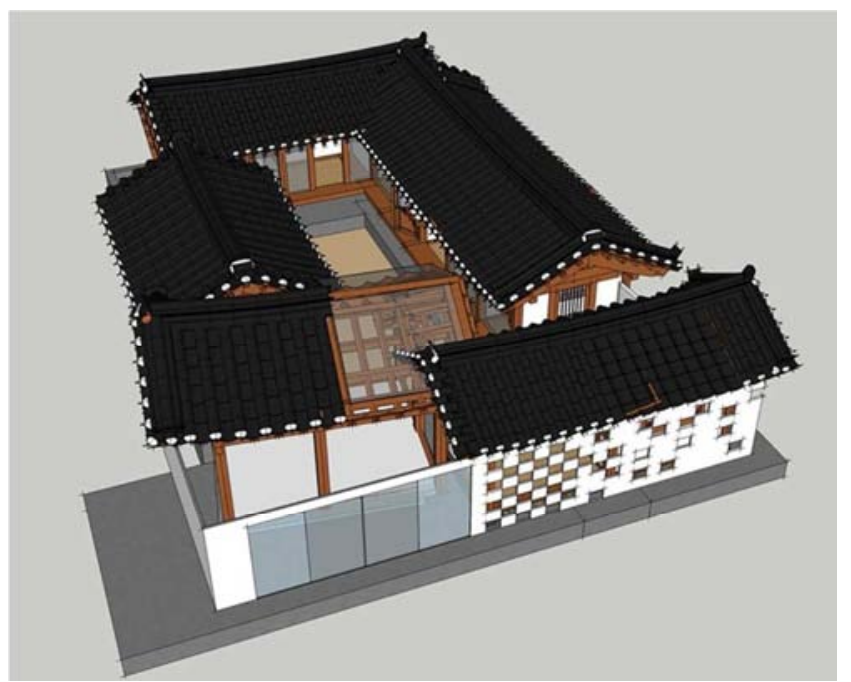

Designed by Huang Zhe, Liu Xinyue, etc

Figure 7. Project 1: Photo-studio model.

Since it was unfavorable for the building to retain the original style with an internal aggregation space, the room layout of the building had been considered carefully in terms of functional quality and personal psychology to arrange etiquette sequence: 1) performing arts, 2) photo taking, 3) changing dresses and 4) leisure. Despite innovations of the project was not all new, its exterior was very reminiscent of HANOK 's faithful traditional form, and it brought with a view to shape and transform human action and historical experience for future generations, which had presented a real challenge to the students who promoted a design philosophy to create new appropriate activities with the minimal renovation.

In spite of heated debates, the term 'society' that comprises the interactive and material aspects of social life has received wide currency in anthropology even today. Some approaches of conservation had tended to integrate traditional culture into modern life. In other words, they were chasing the dream of cultural identity prospered to shape up modern civilization. It is worth mentioning that, unlike the planning methods presented largely in urban development, this project neither intended to blindly imitate the ancient pattern, nor to unscrupulously replace the ancient one by modernity.

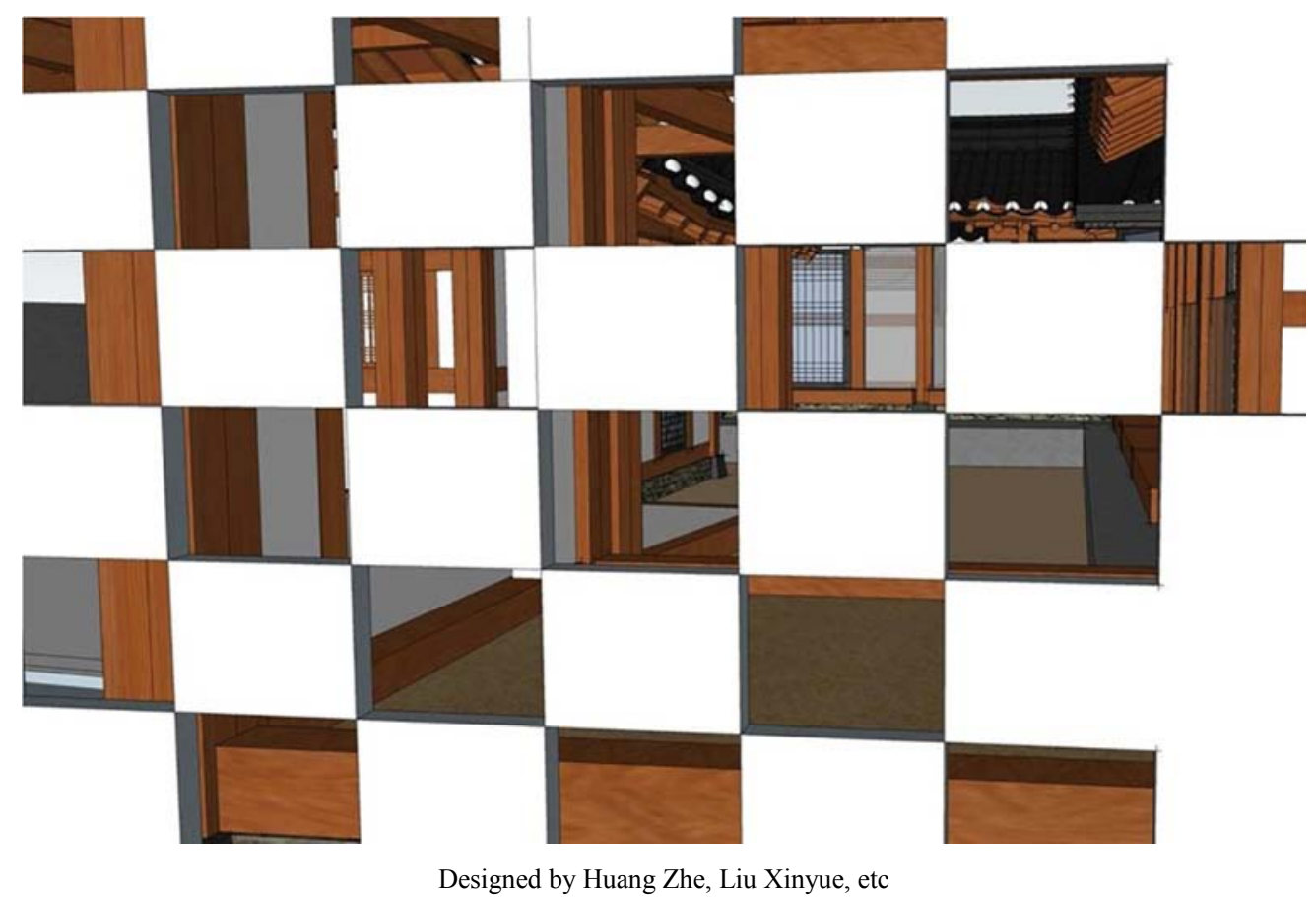

Figure 8. Project 1: Partition wall of Studio.

\subsection{Traditional Symbols}

The second project named 'Tile' provided an interesting installation made by the grey tile to build an interactive cultural center, and in many ways moved the boundary of dwelling into the public domain. The grey tiles of the eaves were the standard for distinguishing the upper and lower classes and could only be used in the building of aristocratic families. There are upturned roofs, eight-character roofs, Yujin Court roofs, triangular wall roofs and so on.
Since there were so many contradictions in the renovation of HANOK space, including enclosed and open space, traditional and modern architectural form, the old and latest life style, the judgement of team researchers was reasonable to determine what a theme be called as 'Conflict' (Figure 9). This work focused on the design of different renewable space of HANOK, namely public space - grey space - privacy space, by only maintaining the principal structure of the building and replacing with modern materials.

The interpretation of 'Tile' came to light in the final achievement. The 'Tile' installation was made of Korea's 
traditional paper, Hanji (Figure 10). Hanji as the traditional Korean paper has been used in books, sketchbooks, and small artifacts, and it has also been used to cover windows and doors because it is durable, and it can last for more than 1000 years because of the unique process by which it is made [7]. In the past, people liked to use the paper to cover the windows and doors, therefore it could play a big role in helping to regulate the interior climate, such as windbreak, light transmitting, temperature and humidity control, and so on. In the East, the 'Tile' is associated with roof materials, but this hasn't stopped it becoming a prestigious and mysterious installation art. The 'Tile' installation hanging indoors, printed with some special texture, was beamed straight into our eyes, just like romantic clouds on the sky, glaring patches of starlight (Figure 11).

\section{Traveler}

Korean teenagers \& old generation
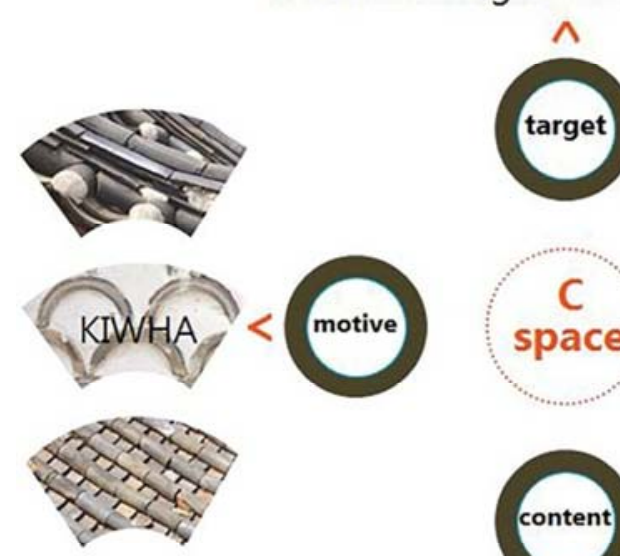

50 pithititis

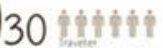

20 itis
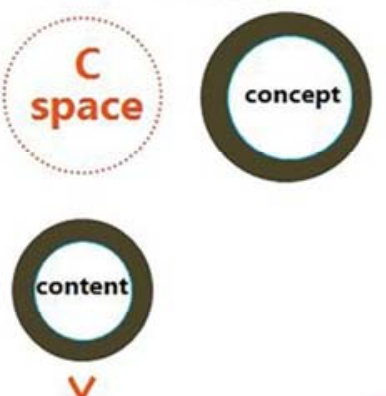

HHH Korean traditional paper HANJI

Designed by Chi Bochen, etc

Figure 9. Project 2: The design concept of tile.

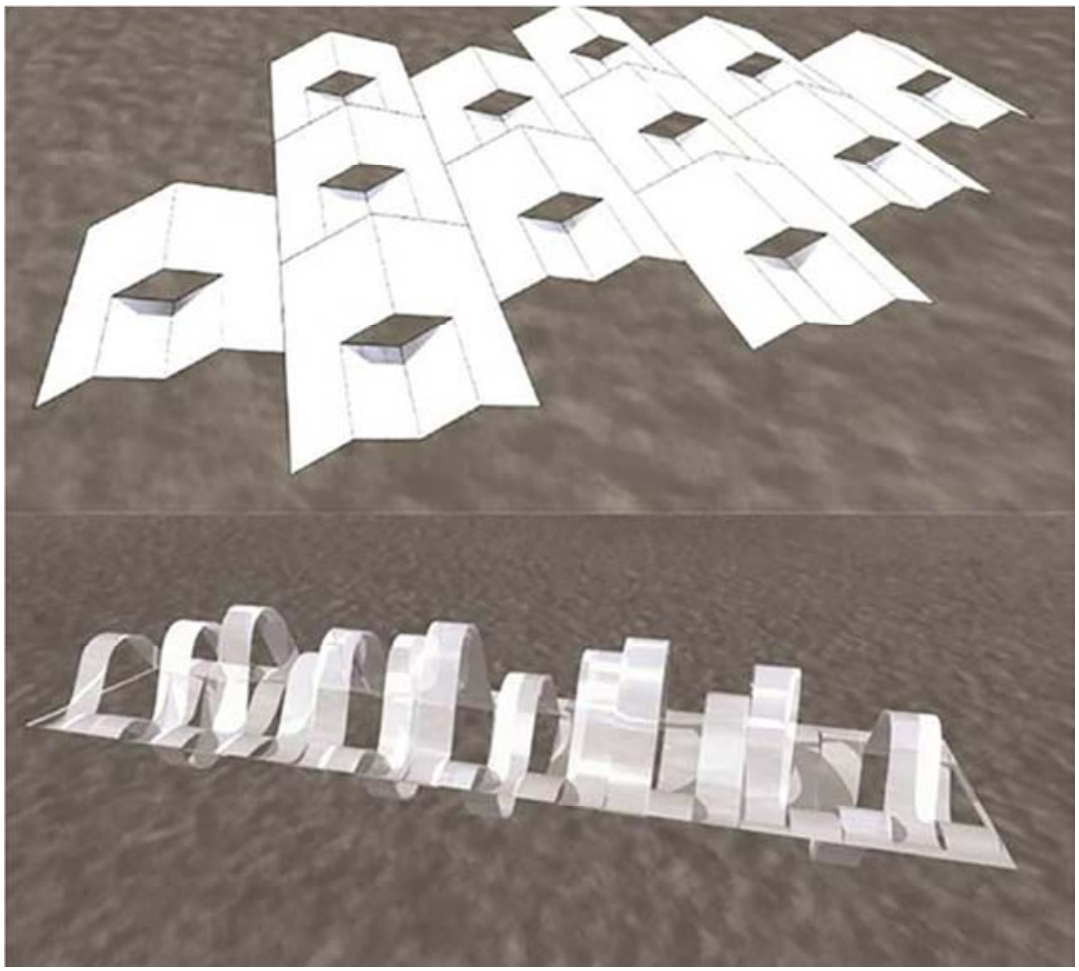

Designed by Chi Bochen, etc

Figure 10. Project 2: Abstract tile made by Korea's paper. 


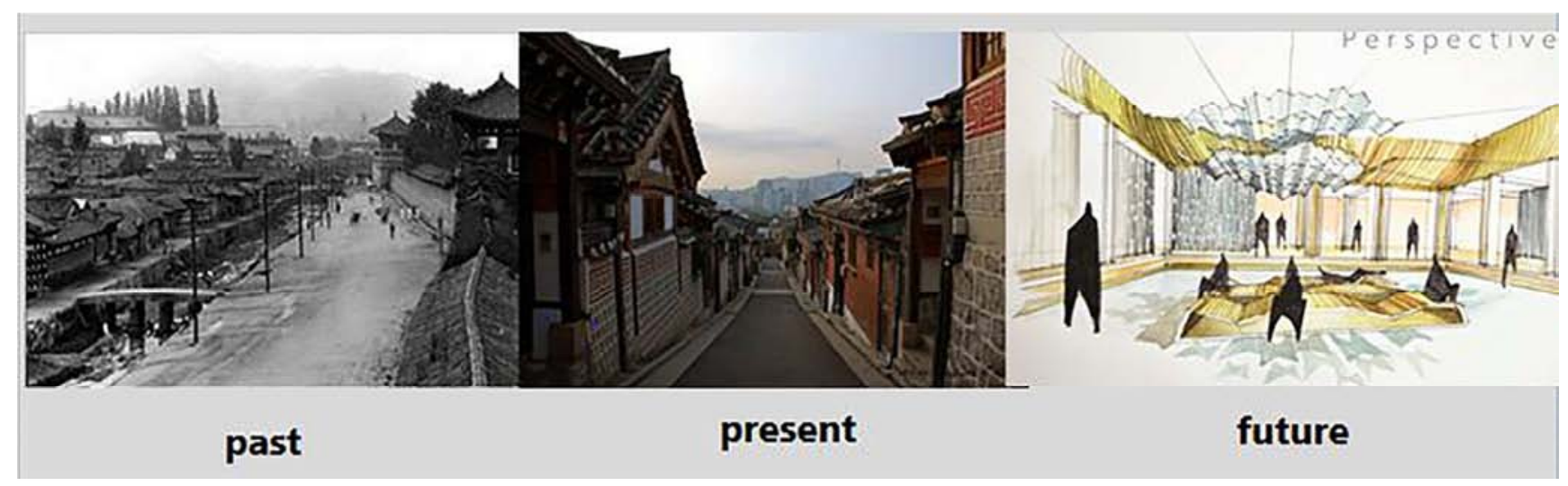

Designed by Chi Bochen, etc

Figure 11. Project 2: HANOK in the past, present and future.

This project tried to guide and explain the principle of art design by using the theory of symbolic function and symbolic character demonstrated in Symbolism. Accordingly, the symbols given to such corresponding areas would constantly increase its attractiveness and its potential for valuing creation.

\subsection{Zen Ideology}

The third team, being aware of that the Buddhist philosophy shaped theories and concepts, made the notion of 'Zen ideology' expand in one direction. In history, Zen began in China in the 6th century CE, spread to Korea in the 7th century CE and to Japan in the 12th century CE, and had become very popular in the West from the mid-20th century. Zen is a kind of philosophy and aesthetics, as well as a kind of design concept ${ }^{[8]}$. According to some Zen traditions, the project with the theme 'Reflection' was just a response to Zen being 'Meditation' to develop its own unique character, attempting to provide different ways to implement this concept, such as the reflection of skylight and the projection of mirror image (Figure 12).

This project was embarking on a new path to find a new model and method for success. 'Reflection', however, could be even more challenging, as there were so many different elements needed to be brought together in order to set the perfect scene. As a result, the project added an underground space in the basement to form a community of contradictions with ground space (Figure 13). In the courtyard, the project adopted ground glass to reflect sky and clouds, which reminded me that souls crossed ages like clouds crossed skies. Although a cloud's shape nor hue nor size don't stay the same, it was still a cloud and so was a soul. The glass whose surface covered with a thin layer of sparse sand was also the ceiling of the underground space. On a sunny day, it allowed sunlight through the glass to project an image down to the underground space, creating a really mysterious atmosphere where people could feel the dappled sunshine in the underground. As the seasons changed, reflected scenery also had different appearance.

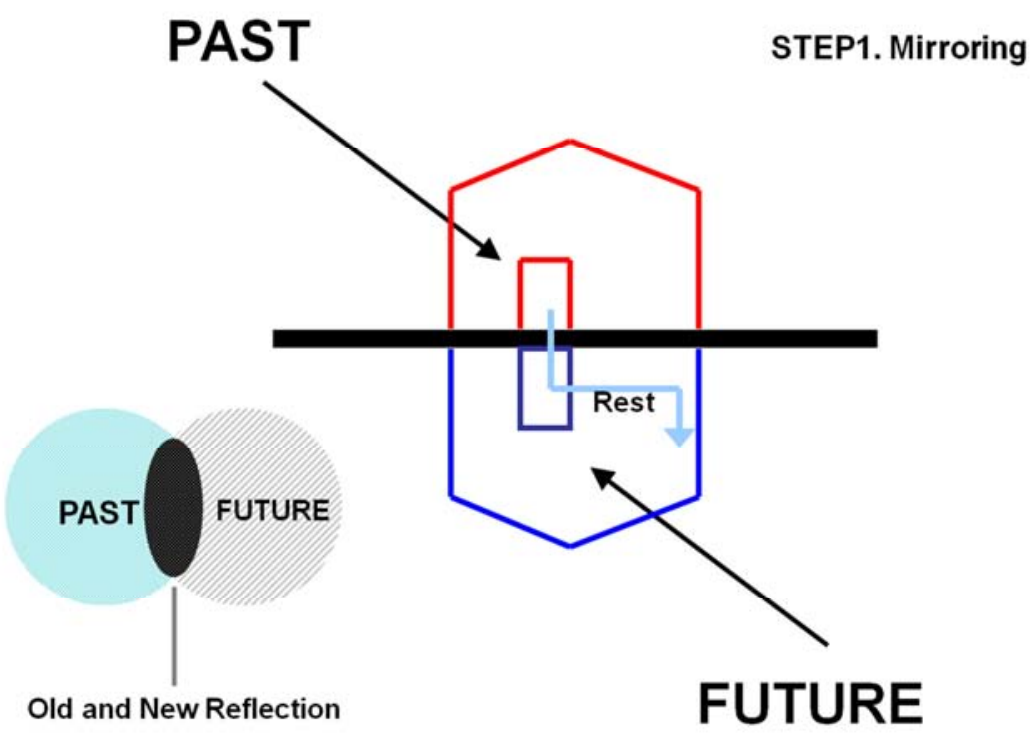

Designed by Wu fengzhou, etc

Figure 12. Project 3: The reflective analysis diagram. 


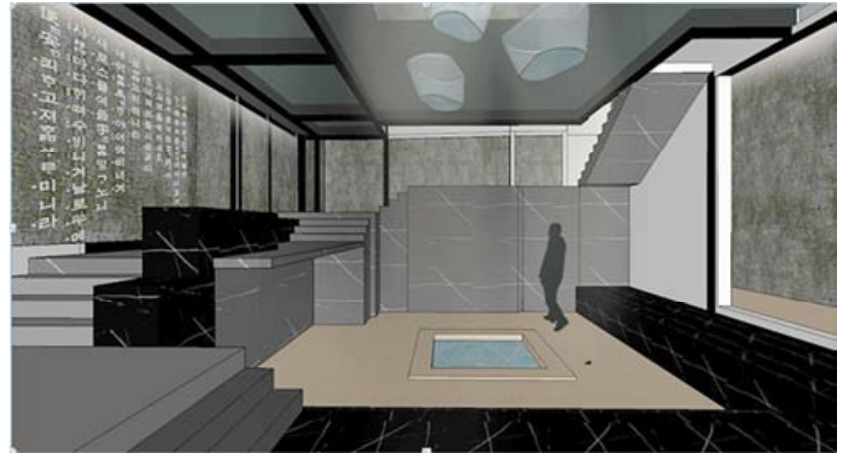

Designed by Wu fengzhou, etc

Figure 13. Project 3: Computer renderings of the reflection.

The view of the model showed that the top space was the mirror image of the bottom, in the same way, the shape of the pool edge of underground floor space also corresponded to the shape of the outdoor platform in the floor courtyard. In contrast, the floor space, the underground part had adopted modern materials like concrete and steel and been endowed with characteristics that related to their natural predecessors such as stone and timber. The two life styles in different containers echoed each other here, which could lead us to the kind of insight that what culture it was, how it manifested itself, and how culture varied around the different forms, it always met the needs of human use.

In light of that Korean housing culture had undergone many significant changes, and the organization of interior housing space had also dramatically changed, with each space developing a different physical form and with the connections between each space also having been altered, the conception of 'Reflection' attempted to connect the modern and traditional society to reflect Zen through the physical and inner world and transform Zen into a kind of wisdom in our life. When Zen's artistic conception and design are combined, new beauty is created [9].

\section{Conclusion}

After a week of joint design communication and learning, an international design culture collision had staged here and successfully finished. In 2013, the Students Workshop adopted a design teaching mode of mixing students from different regions into groups and guiding them by teachers from different institutions respectively. In the process, teachers and students from different regions lived together, learned from each other, shared different opinions and became tacit understanding. The open and international design teaching mode allowed the teachers and students to fully understand the meaning of interaction, participation and teamwork, which was unmatched by daily learning and so became the valuable experience of AIDIA Students Workshop. There is no doubt that through the cognition and learning of different cultures in other countries, we could further reflect on the original intention of human construction and the significance of protection.

In China, there are also some problems such as the lack of urban characteristics, worrying cultural inheritance, illegal construction and large-scale demolition [10]. These crises urgently require us to make some actions to implement urban remediation and organic renewal in an orderly manner aiming at improving the environmental quality of the old city, sorting out the spatial order of the old neighborhood and restoring the function and vitality of the old city.

\section{References}

[1] WooMi Jo, Choong-Ki Lee, Yvette Reisinger. Behavioral intentions of international visitors to the Korean hanok guest houses: Quality, value and satisfaction. Annals of Tourism Research. Vol. 47, 2014, pp. 83-86.

[2] Zhu Caiqing. Histroy, Present and Future-Investigation and Enlightment on the Subject of Urban Renewal in South Korea and Japan. City \& House. Vol. 23, No. 4, 2016, pp. 6-9.

[3] Zhang Jianhua. Korean modern architecture development process and national cultural trend. Architectaral Journal. No. 4, 2002, pp. 61-64.

[4] Xu Yanwen. Korean traditional houses. Shanghai Real Estate. No. 6, 2013, pp. 59.

[5] Cui Xiangri. Discussion on the traditional living culture of China, Japan and Korea. Success (education). No. 23, 2013, pp. 298.

[6] Editorial Department of the Journal. Hanok: No comparison with natural scenery. Folk Custom in China. No. 6, 2014, pp. 65-66.

[7] Jong-il Choi, Yong Jae Chung, Dai Ill Kang, Kyu Shik Lee, Ju-Woon Lee. Effect of radiation on disinfection and mechanical properties of Korean traditional paper, Hanji. Radiation Physics and Chemistry. Vol. 81, No. 8, 2012, pp. 1051-1054.

[8] Qin Ya-ping. Analysis on Zen Meaning of Interior Space Art. Journal of Tianjin Institute of Urban Construction. Vol. 17, No. 3, 2011, pp. 157-161.

[9] Wu Jicai. The application of Zen design ideas in materials. Northern Literature. No. 9, 2012, pp. 103.

[10] Yang Guiqing, He Jiangxia. Literature Research and Value Analysis of Organic Renewal of Traditional Community. Shanghai Urban Planning Review. No. 5, 2017, pp. 12-16. 